\title{
From Chance to Serendipity: Knowledge Workers' Experiences of Serendipitous Social Encounters
}

\author{
Ekaterina Olshannikova (iD, ${ }^{1}$ Thomas Olsson $\left(\mathbb{D},{ }^{1}\right.$ Jukka Huhtamäki $\left(D^{2}{ }^{2}\right.$ \\ Susanna Paasovaara $(\mathbb{D}),{ }^{1}$ and Hannu Kärkkäinen $(\mathbb{D})^{2}$ \\ ${ }^{1}$ Faculty of Information Technology and Communication Studies, Tampere University, Kalevantie 4, 33100 Tampere, Finland \\ ${ }^{2}$ Faculty of Management and Business, Tampere University, Korkeakouluntie 8, 33720 Tampere, Finland \\ Correspondence should be addressed to Ekaterina Olshannikova; ekaterina.olshannikova@tuni.fi
}

Received 7 October 2019; Revised 2 December 2019; Accepted 27 December 2019; Published 14 February 2020

Academic Editor: Francesco Bellotti

Copyright (C) 2020 Ekaterina Olshannikova et al. This is an open access article distributed under the Creative Commons Attribution License, which permits unrestricted use, distribution, and reproduction in any medium, provided the original work is properly cited.

\begin{abstract}
Serendipity refers to uncontrolled circumstances that lead to unexpected yet fortunate discoveries. The phenomenon has been studied extensively in relation to information retrieval. However, serendipity in the context of social encounters has been the subject of few empirical studies. In professional life, social serendipity might result in benefits such as fruitful collaboration, successful recruitment, discovery of novel information, and acquisition of crucial new perspectives from peers. Despite the potential significance of serendipity, particularly for knowledge work, there is a lack of empirical understanding of related subjective experiences and the role of technology within the process of encountering unsought findings. This qualitative study investigates knowledge workers' detailed narratives of serendipitous social encounters and the related factors through an analysis of 37 responses to an international online survey. We provide a detailed account of the experiential characteristics and contextual qualities of the reported instances of social serendipity. Finally, we discuss the seemingly minor role of technology in social serendipity and research avenues to computationally enhance social serendipity.
\end{abstract}

\section{Introduction}

Originating in the $18^{\text {th }}$ century [1], the concept of serendipity has been researched as a phenomenon of uncontrolled circumstances that lead to unexpected yet fortunate discoveries [2]. Serendipity unfolds as the personal ability [3] to benefit from happy accidents [4]. The general notion of serendipity has been studied extensively in relation to creativity and innovation activities $[5,6]$, information retrieval $[7,8]$, and knowledge building and learning [9, 10]. Consequently, serendipity has often been conceptualized as chance or luck [11-13], particularly in the context of innovation processes and scientific discoveries.

Earlier research in human-computer interaction (HCI) and computer-supported cooperative work (CSCW) was designed to capture serendipity within established work environments, with the aim to facilitate intraorganizational knowledge creation and dissemination. As a result, two research approaches have emerged [14]: the exploration of natural serendipity (entirely unpredictable, nondeterministic, and nonfacilitated) and design for artificial serendipity (facilitated or triggered with the help of artificial agents such as information communication technology (ICT) applications). Natural serendipity has been approached in exploratory studies on daily, spontaneous encounters [15] and social awareness [16] in co-located work environments. Constructive research on artificial serendipity has focused on designing systems that enable chance encounters or so-called impromptu encounters [17], with the aim to enhance social awareness and interactions among collocated or distributed workers. In the context of information retrieval, a typical example of artificial serendipity is enabling surprising, novel discoveries in content-based recommender systems to improve the diversity of recommendations [18-20].

While much CSCW and HCI research has focused on understanding and supporting the elements of chance and 
surprise, we agree with theories stressing that chance encounters do not always lead to serendipitous events. The element of benefits is equally central, as emphasized by research on information search and ICT [21-23]. The subject of this article, therefore, is an exploration and analysis of how chance encounters turn into professionally valuable experiences of social serendipity (the example story in Figure 1), followed by a discussion of how ICT can better support this process. We focus on encounters between knowledge workers or people in professions that require high levels of creativity, extensive use of intellectual skills, and theoretical rather than contextual knowledge [24]. According to Davenport [25], knowledge workers possess "high degrees of expertise, education, or experience and the primary purpose of their jobs involves the creation, distribution, or application of knowledge."

Highly networked and collaborative, modern knowledge work can benefit from social serendipity because workers' tasks often require extensive social networks, various types of information, and access to people with complementary expertise [26]. It is noteworthy that, in today's knowledge work practices, value is often created in an ecosystemic way [27] and through social networks [28]. Organizational fluidity [29] relaxes conservative boundaries and structures, allowing networking and collaboration to take place more freely within and among organizations, cultures, and disciplines. Such changes in collaboration and networking practices have introduced new interest in fostering serendipitous encounters regardless of actors' affiliations and across organizational boundaries. We anticipate that such interorganizational social serendipity can manifest in, for example, forming new, useful connections at networking events and recruitment fairs, identifying relevant peers at conferences, and establishing fruitful business relationships in cocreation spaces and start-up incubators [30].

We argue that the experience of social serendipity that takes place naturally outside the workplace is an indicator of successful, desirable knowledge work. For individual, social serendipity can be a highly beneficial experience, providing both emotional pleasure and instrumental gain. Designing information systems for facilitating serendipity could benefit from deeper empirical understanding of what examples people have of such experiences and how social serendipity emerges as an experience. This knowledge, in turn, could shed light on the expected role of ICT in social serendipity processes and how technology can contribute to formation and flow of serendipitous experiences in professional life.

This research is driven by the following questions: (RQ1) What characterizes serendipity in the context of social encounters among knowledge workers? (RQ2) What behavioral and experiential processes are associated with social serendipity? Through an analysis of 37 knowledge workers' selfreported narrations of their experiences of serendipitous social encounters, we provide a detailed account of the various experiential and contextual qualities that impact social serendipity. Additionally, we extend the theoretical understanding of the traditional serendipity process with characteristics particularly applicable to social serendipity.

\section{Related Work}

This section first dives deeply into the concept of serendipity and describes relevant theories and studies to identify the research gaps we address in this article. Second, we review the existing research that envisions opportunities to artificially support serendipity via various technological solutions.

2.1. Theoretical Foundations of Serendipity. The conceptualization of serendipity began in 1754 through the story about "The Three Princes of Serendip" who were "always making discoveries, by accidents and sagacity, of things they were not in quest of" [31]. The term gained popularity in the late $20^{\text {th }}$ century in a detailed discussion on serendipity as "the art of making unsought findings" [32]. Researchers theorizing serendipity were primarily interested in the role of chance or luck in scientific discoveries. An alternative definition appeared in the work of Liang [33], who studied the concept as an experiential quality within interactive technologies and defined it as a "pure experience in our everyday lives interwoven with a tangled ecology of interactive systems."

Many researchers have investigated serendipity in the domain of information retrieval and produced various frameworks and theories of its elements under different names despite major similarities in their meanings. According to Makri and Blandford [21], serendipity can be initiated by a conducive physical environment in the absence of time pressures. Other researchers labelled these features as triggers [22, 23]. Makri and Blandford [21] noticed that to benefit from serendipity, one should also have an implicit awareness of the need or opportunity for unsought discoveries and an open mind to sense-making of serendipitous cues. These observations are reflecting the notion of the prepared mind proposed by Pease et al. [22] and the element of connection in the model developed by McCay-Peet and Toms [23]. The final element common across all models of serendipity is the so-called serendipitous or valuable outcome, which might refer to the creation of a product, artifact, or knowledge.

In addition to these process-based models, Sun et al. [34] and Zhou et al. [35] developed a serendipity model based on three types of contexts that impact the serendipitous experience. First, the external context refers to the role of personal status and temporal and environmental factors, for example, encountering unsought findings during activities such as leisure and work in a specific place and at a certain time. Second, the social context relates to unexpected encounters achieved through socializing with both familiar and unfamiliar others. The external and social contexts thus facilitate perceptions of unexpectedness through various surrounding stimuli, reflecting the earlier conceptualizations of conducive physical environments and triggers. Finally, the internal context comprises the role of individuals' background knowledge, experiences, mindsets, recognized needs, emotional states, and levels of perceptiveness. This context is 


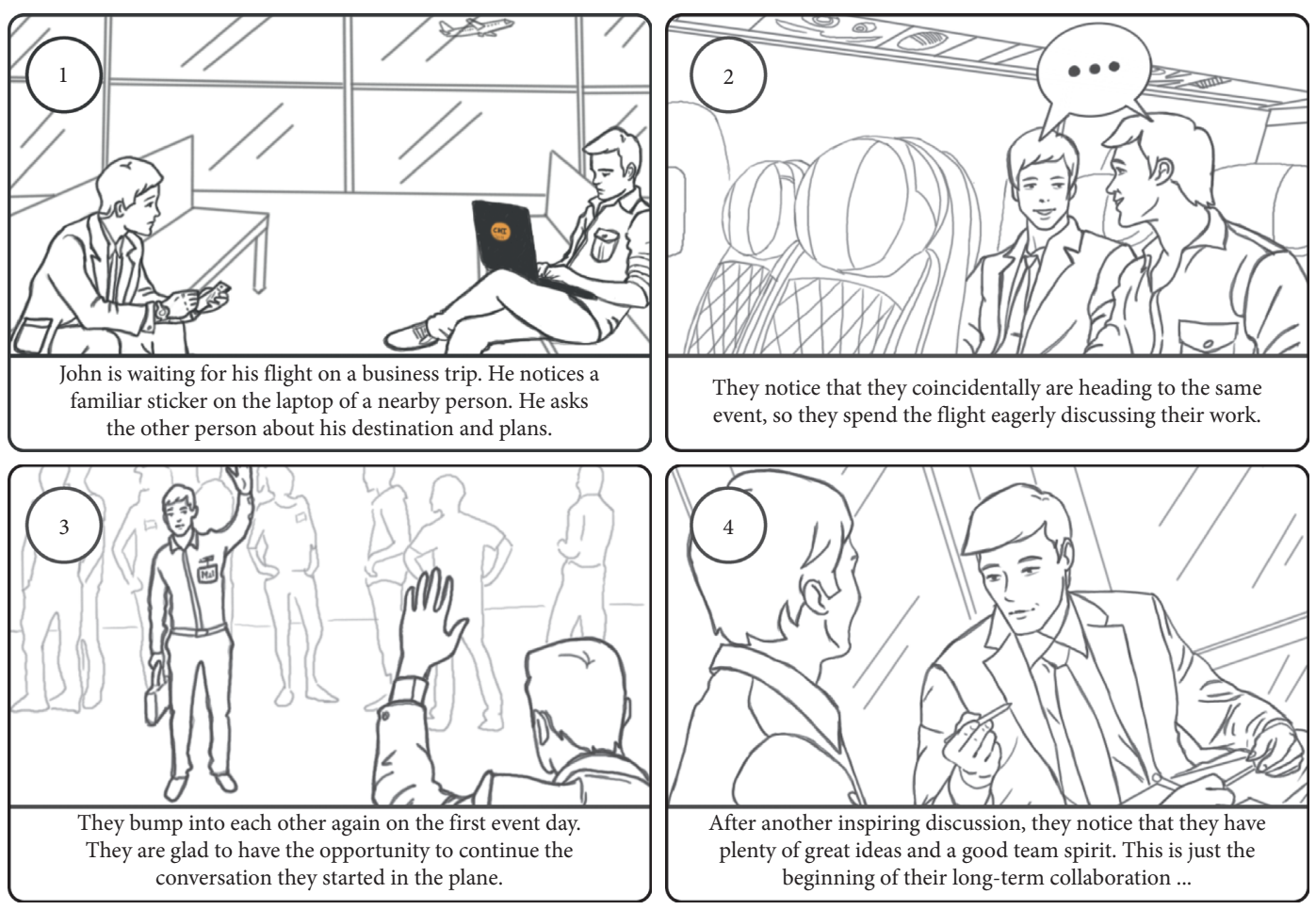

FIgURE 1: Fictional example of an unexpected encounter that turns into social serendipity.

tied to the sense-making of unexpected encounters and value creation. The focus on individuals' characteristics in this view on serendipity can be clearly associated with the notion of the prepared mind, while the sense-making element of the proposed model correlates with the notions of connection and valuable outcomes mentioned earlier.

In this article, we adopt McCay-Peet and Toms's [23] model as the central theoretical framework and analytic tool for the collected experiences of serendipity. Reviewing existing models that theorize serendipity as a process and propose a temporal framework also allows us to analytically dissect the experiences collected through the survey. McCayPeet and Toms [23] distinguished the following phases of the serendipitous experience. The trigger initiates the serendipity experience and thought process about a potentially valuable outcome. The experience can arise from visual nontextual cues such as observations of activities and environments, verbal cues in conversations among individuals, and textual cues from reading content in books, journals, and websites. In the connection phase, a person relates the trigger with their background and knowledge, which leads to identification of a valuable outcome, defined as the potential to solve an existing problem or open new opportunities. The follow-up phase consists of the actions a person takes to achieve a valuable outcome such as capturing the trigger for later use, immediately acting on the opportunity, or preparing to accomplish a valuable outcome. McCay-Peet and Toms [23] also identified three key categories of valuable outcomes that have personal, organizational, and global effects. An unexpected thread is a sign that, when perceived by a person, indicates the presence of luck, chance, accident, or surprise in a serendipitous situation. We apply this model in the analysis of the reported experiences and explore its validity in the context of social serendipity in knowledge work.

In summary, according to earlier conceptualizations of serendipity, to take advantage of serendipity, one should have an open mood and free time to turn opportunities into action. A person should be able to perceive and analyze serendipitous cues from the environment to gain benefits. Following this broad theorization, we want to emphasize that experiences other than luck and chance must unfold to fulfil the requirements of the serendipity definitions. It is noteworthy that serendipity takes place in the realm of experiencing, which does not permit objective examination or measurement. Both essential elements of serendipity-unexpectedness and benefits-are primarily subjectively defined. The question of what is sufficiently unexpected or beneficial to count as serendipity varies among individuals. It, therefore, remains unclear how the natural contingency in everyday social encounters turns into something recognized as useful. Some long-term effects such as the increased productivity of individuals and organizations and the creation of new ideas can be recognized objectively. However, it is almost oxymoronic to empirically study the interplay between the experience and long-term effects of serendipity. It is difficult for individuals to distinguish between the experienced realm and physical reality [36], so rendering the scientific study of such concepts remains challenging. Perhaps due to this experiential nature, most theorizations of serendipity are limited to describing the internal and external factors that contribute to the probability of a particular event such as finding a new interesting connection. To our knowledge, particularly in our 
interest area of knowledge work, there are neither proper conceptualizations nor prior empirical studies on individuals' subjective experiences of the overall social serendipity process from the trigger to the valuable outcome.

\subsection{Designing for Serendipity}

\subsubsection{Key Affordances for Artificial Serendipity.} Serendipitous experiences triggered or initiated by physical and digital objects, agents, or environments have been termed artificial serendipity [14]. The concept also appears in the literature where it is called controlled [37] and online serendipity [38, 39]. In contrast to its natural counterpart, which is entirely unpredictable and nondeterministic, artificial serendipity happens only when necessary conditions occur. De Melo [14] classified four categories of triggers for serendipity (Table 1): things, places, events, and agents.

Such physical and digital triggers might possess key affordances for serendipity, as conceptualized by Björneborn [40]. The first affordance-so-called diversifiability-describes the capacity of environments to enable access to diverse, dissimilar, and incomplete contents. This affordance, coupled with individuals' ability to be open-minded, can spark curiosity and interest. The second affordancetraversability-refers to the environment capacity to enable individuals' mobility, leading to divergent exploration and convergent search activities. The most rudimentary examples of diversifiability and traversability affordances in the digital realm are the Google search engine and Twitter feeds, which increase the chances for serendipity to occur by opening access to enormous amounts of contents and different paths to encounter them. As an example of a physical environment with these two affordances, Björneborn [40] mentioned libraries. Finally, sensorability relates to the degree of stimuli richness in the environment and the capacity to stimulate the serendipitous experience through various senses. Coupled with individuals' sensitivity and attention, sensorability is responsible for producing a sense of surprise and experience. To summarize, diversifiability and traversability manifest in both physical and digital environments and have stronger effects in the latter due to the ease of accessing and manipulating information. Sensorability primarily manifests within things and trigger agents. Digital triggers typically are limited to visual and audio stimuli, so the sensorability affordance is prevalent within the physical realm involving all the senses.

Digital environments' potential to have affordances for serendipity was addressed by McCay-Peet and Quan-Haase [41], who argued that dynamic, diverse virtual environments can become engines of serendipity. The nature of dynamism and diversity as key qualities of digital environments can be correlated to the diversifiability and traversability affordances. McCay-Peet and Quan-Haase [41] studied users' perceptions of Twitter as a serendipitous environment to outline a design space for future serendipity-embedded digital services. The main finding from their research was that greater activity on such platforms can strengthen perceptions of serendipity and increase the probability of opportunistic information discovery (i.e., divergent content exploration). Additionally, the authors concluded that perceptions of serendipity might vary due to age differences and might be influenced by the various motivational factors behind the use of social platforms.

In contrast, Lutz et al. [42] challenged the possibility of serendipitous online experiences, arguing that algorithms might decrease the element of surprise in discovery. The authors demonstrated that Internet is perceived as a serendipitous engine due to the abundance of transparent information available for discovery. In addition, the authors confirmed that serendipity depends on trust and privacy, which can either prevent or establish the context for offline and online serendipity. They also found that people with mindsets prepared for opportune discoveries have fewer trust and privacy concerns. Thus, prior research has demonstrated the interplay of external affordances related to various physical and digital triggers and internal affordances related to individuals' characteristics and abilities.

\subsubsection{Supporting Serendipitous Social Encounters.} Although earlier CSCW and HCI research did not refer directly to the term "social serendipity," several concepts are somewhat related to the phenomenon. For example, Kiesler and Cummings [15] found that frequent, informal, spontaneous interactions in collocated work environments enable cohesive relationships among knowledge workers and increase their social awareness. Similarly, Vyas et al. [16] suggested that spontaneous encounters play significant roles in working life because employees in organizations rarely have opportunities for direct interactions that make them aware of others' activities. In particular, regarding the role of physical places that trigger such encounters, Brown et al. [43] concluded that the workspace layout may facilitate unplanned, casual interactions among employees and can serve as a contextual cue for enhanced communication and productivity in organizations.

Such exploratory studies have motivated various system designs to increase the probability of chance encounters and overall social awareness within organizations. For instance, Erickson and Kellogg [44] introduced the concept of socially translucent systems aimed at increasing the visibility of employees' activities in large groups and organizations. Jeffrey and McGrath [17] designed the "Forum," a collaborative working environment as a space for informal online interactions that help employees make new connections and share knowledge.

Studies on social matching have also been aimed at understanding the role of both personal (internal) and contextual (external) factors in supporting serendipitous encounters between strangers $[45,46]$. Eagle and Pentland [47] proposed research on sensing contextual surroundings and increasing serendipitous interactions via mobile devices. They built an artifact called serendipity, a socially curious mobile device that encourages face-to-face interactions within a range of proximity. Interestingly, this solution is based on the idea of maximizing similarity in the matching process, which might lead to anticipated rather than serendipitous encounters. 
TABLE 1: Examples of physical and digital triggers that can initiate artificial serendipity.

\begin{tabular}{|c|c|c|c|}
\hline & Trigger type & Physical & Digital \\
\hline What & Things & $\begin{array}{l}\text { Inanimate material objects (e.g., pens, desks, cups, } \\
\text { desks, and plants) }\end{array}$ & $\begin{array}{l}\text { Digital artifacts (e.g., notifications, buttons, and pop- } \\
\text { up windows) }\end{array}$ \\
\hline \multirow{2}{*}{ Where } & Places & $\begin{array}{c}\text { Physical environment (e.g., buildings, rooms, office } \\
\text { premises, streets, and parks) }\end{array}$ & $\begin{array}{l}\text { Digital environment (e.g., social networking } \\
\text { platforms, mobile applications, and video games) }\end{array}$ \\
\hline & Events & $\begin{array}{c}\text { Co-location (e.g., physical presence at conferences } \\
\text { and parties) }\end{array}$ & $\begin{array}{l}\text { Distributed events (e.g., teleconferences, webinars, } \\
\text { and a remote presence) }\end{array}$ \\
\hline Who & Agents & $\begin{array}{l}\text { Animate beings (e.g., human beings, pets, and } \\
\text { animals) }\end{array}$ & $\begin{array}{c}\text { Artificial beings (e.g., chat-bots and artificial } \\
\text { intelligent agents) }\end{array}$ \\
\hline
\end{tabular}

Another vein of research and design has sought to measure serendipity despite the highly subjective nature of the phenomena. For instance, Losada et al. [48] attempted to predict the probability of experiencing fortunate discoveries by exploring phone calls and Bluetooth-based social interactions between employees in organization during a ninemonth experiment. The authors concluded that analysis of social networks could reveal information about experiencing serendipitous encounters when establishing new connections. Niu and Abbas [49] further proposed a framework to stimulate users' curiosity through modeling surprise and value in recommender systems.

Some recent commercial services have been aimed at increasing serendipitous encounters among people. Examples include the Serendipity Machine (serendipitymachine. com) social platform and the Seats2Meet (seats2meet.com) service. Both are driven by the vision of Society 3.0 [50], which refers to virtual communities that contribute to social capital, business networks, and ecosystems through social networking and cocreation. The primary objective of Seats2Meet is to arrange social interactions through realtime, location-based networking. The service provides software to support and facilitate connections, follow-up activities, and value creation. Unfortunately, so far, the service has been little used, possibly because it is firmly tied to physical meeting points.

These studies and designs have demonstrated that understanding context plays a vital role in increasing the chances for the element of surprise to occur. However, not all unexpected and impromptu connections evolve into beneficial, that is, serendipitous experiences. People also have to recognize opportunities and act promptly. Although the concept of serendipity has inspired various system designs, earlier CSCW and HCI investigations narrowly focused on intraorganizational boundaries and tended to simplify serendipity by treating only the initial phase of the serendipity experience that enables chance. While enabling chance encounters is worthwhile, we call for design endeavors that aim further-towards social serendipity. This end demands new design approaches to turn mere chance and contingency into beneficial outcomes with the help of algorithmic systems. We propose that knowledge work can benefit from designs that better utilize diversity and dissimilarity principles to bridge people with different expertise. Technology can also take more agencies in assisting knowledge workers to follow up on their new connections and uncovering professional values that could otherwise go unseen due to human biases [51]. We continue this line of discussion based on the empirical study, as follows.

\section{Methodology}

To collect knowledge workers' experiences of serendipitous social encounters, we employed an international, Englishlanguage online survey with open-ended questions accompanied by Likert statements. We anticipated that finding relevant respondents with interesting experiences would be challenging. We, therefore, decided to focus on a qualitative approach by including several open-ended questions rather than a quantitative approach with many closed-ended questions that would not allow an in-depth understanding of the experiences.

3.1. Online Survey Structure. To explain the purpose of the survey, we introduced serendipity as the experience of unexpected social encounters that are perceived as fortunate and result in personally valuable interactions, networks, information, and other outcomes from social interactions. This definition was informed by the aspects and essential elements of serendipity drawn from the theories introduced in Section 2. We also supported this explanation by including a storyboard (Figure 1) to the introductory part of the survey.

After reading and signing the informed consent form, the respondents proceeded to the questionnaire, which had five sections (Table 2). The first section focused on the respondents' experiences of social serendipity and included questions about the total number of such encounters and short descriptions of their most memorable ones (Q1 and Q2 in Table 2). The second section asked for a detailed description of their most memorable or important experience (Q3 and Q4). Earlier research has demonstrated significant role of context [35], so the third section included 7-step Likert statements and open-ended questions about the physical, social, and personal contexts of the reported encounter (Q5-Q10). The fourth section asked for details about attitudes, similarities, and differences with the encountered person (Q11-Q14), as well as follow-up activities and valuable outcomes (Q15-Q17). Section five investigated the respondents' opinions and ideas about ICT-enhanced serendipity (Q18 and Q19). Finally, the survey collected the respondents' demographic details, attitudes toward technology, social media use, and general social networking practices. 
TABLE 2: Online survey structure and verbatim questions.

I. General information regarding serendipitous experiences

Q1. Overall, how many serendipitous encounters do you think you have experienced?

Q2. What portion of these was somehow successful and led to positive results in your work?

II. Most memorable experience

Q3. Please shortly describe what kinds of experiences or moments they were. Did they have something in common?

Q4. Now, think of your personally most important experience or moment. If it is hard to decide between a few alternatives, it might be best to concentrate on the one that you remember the best. For the selected experience, we would like you to verbalize the first encounter from your perspective in as much detail as possible. Feel free to write a short story of the moment in your own way.

III. Context

Q5. The place where we met was to me: (1) very unfamiliar-(7) very familiar.

Q6. The other surrounding people around were to me: (1) very unfamiliar-(7) very familiar.

Q7. What were your first feelings or impressions after the meeting?

Q8. Your willingness to socialize at that moment: (1) very unsocial-(7) very social.

Q9. Busyness: (1) I was in a great hurry-(7) I was not busy at all.

Q10. Energy level: (1) I was very tired-(7) I was full of energy.

IV. Attitude, follow-up, and valuable outcome

Q11. Please rate how different your interests were from the person you met: (1) very different-(7) very similar.

Q12. If you identified common interests with the person you met, please briefly describe what they were about.

Q13. Please rate how different your personality is from the person you met: (1) very different-(7) very similar.

Q14. Please describe how comfortable you were while interacting with the person you met: (1) very awkward-(7) very comfortable.

Q15. What were the long-term results of this encounter? How has this encounter been valuable to you and your work?

Q16. How and when did you realize that this encounter or new connection was valuable?

Q17. In your opinion, what made it possible to take advantage of this encounter or new connection?

$V$. Ideation on ICT-enhanced serendipity

Q18. How do you think information technology (e.g., mobile applications, online services, and social media) could support serendipitous encounters?

Q19. What kind of technical features could help people discover each other or help people meet?

The online survey questions were partly inspired by McCay-Peet and Toms's [23] model of the serendipity process. For instance, the third section was aimed at eliciting details on contextual factors that could serve as triggers for serendipity. Q15-Q17 were intended to collect details on the phases of follow-up, connection, and valuable outcomes, according to the process model.

3.2. Recruitment and Respondents. We targeted knowledge workers, whom we defined in the survey as "people who develop or use knowledge in their job (e.g., researchers, engineers, consultants, teachers, and coaches)." The respondents were recruited through mailing lists and flyers at academic events, as well as web-based platforms, such as the Call for Participants service, (callforparticipants.com) Facebook, LinkedIn, and Twitter. As an incentive, the respondents were invited to take part in a raffle for an iPad and two $\$ 50$ Amazon vouchers. We closed the survey after collecting 50 responses over several months, which we considered a sufficient amount for qualitative analysis. Of the 50 respondents, 37 provided sufficient details about serendipitous social encounters that had effects on their professional life. The other 13 stories were excluded because they either were focused on nonprofessional benefits such as love stories and friendships or were about general opinions regarding serendipitous experiences without specific examples from their lives.

The respondents' ages ranged widely from 22 to 77 years ( $M$ : 35 and Mdn: 30). Nineteen respondents were female and 18 male, and they primarily came from European and Slavic backgrounds: Finnish $(N=12)$, Russian $(N=11)$, British $(N=3)$, and Czech $(N=3)$. The rest were Slovakian, Greek, American, Indian, Kazakh, Persian, Italian, and Yemeni. At the time of completing the survey, the majority of the respondents were pursuing doctoral studies $(N=15)$, five were Master of Science students and one was an undergraduate student. Seven respondents had received undergraduate degrees, six Master of Science degrees, and three doctoral degrees. Researcher $(N=9)$ was the most common occupation among all the respondents. Some reported working in ICT as, for example, data architects, software engineers, and computational physicists. The remaining professions included, for example, business owners, health care experts, designers, management, and sales specialists.

The majority of the respondents indicated that they had experienced only a few serendipitous social encounters in their lives (average: 7, minimum: 1, maximum: 30, and standard deviation: 6). For 21 respondents, most of the new, unexpected connections ( $>50 \%)$ had evolved into serendipitous experiences that positively affected their work. For 13 respondents, less than $50 \%$ of the encounters were useful in their professional life, and for the remaining respondents, it was hard to estimate proportions of professionally valuable serendipitous social encounters. Most respondents reported that they were somewhat social and somewhat proficient in becoming acquainted with new people ( $M: 4.96$ and Mdn: 5). On average, the majority $(N=25)$ had $100-500$ friends in social networking services, while nine respondents had more than 500 connections and three respondents had fewer than 100. Interestingly, many respondents were not especially active or strategic in networking ( $M: 4.37$ and Mdn: 5). They 


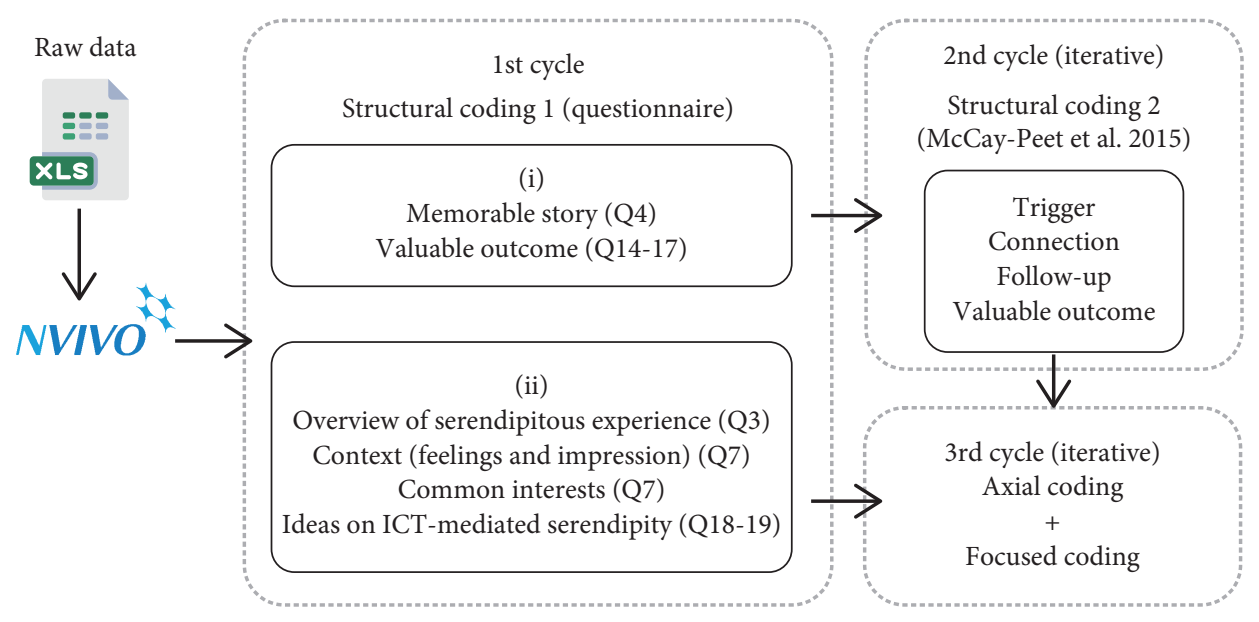

FIGURE 2: The process and methods of qualitative coding.

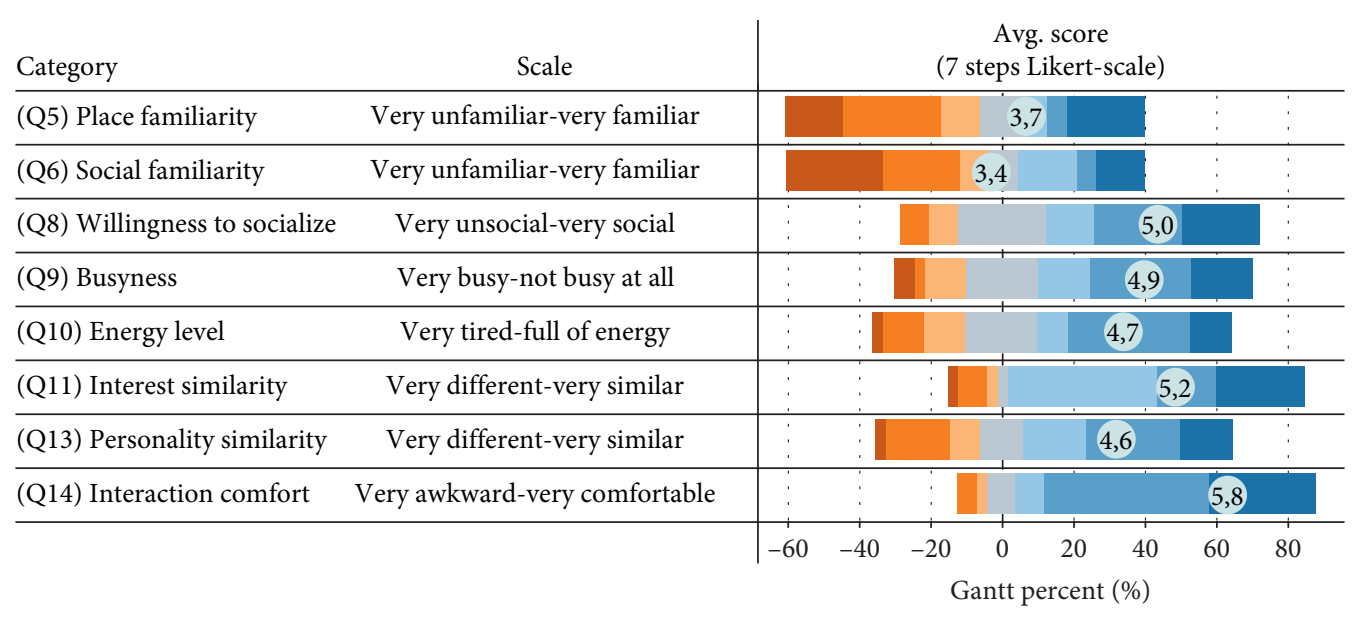

FIgURE 3: Attributes of the respondents' serendipitous social encounters.

considered themselves to be empathetic (M: 5.6 and Mdn: 6) and somewhat pleasant and easy to interact with (M: 5.3 and Mdn: 5). Most agreed that their work related to knowledge and information acquisition (M: 5.73 and Mdn: 6), and their jobs required active collaboration with others ( $M$ : 5.36 and Mdn: 6). The respondents generally were positively oriented toward technology (M: 5.32 and Mdn: 6). Overall, their job descriptions and backgrounds fit well with what could be considered to be knowledge workers. Although not used in the statistical analysis (e.g., comparisons between different groups based on background variables), such data could help planning follow-up studies with more quantitative approaches.

3.3. Data Analysis. The quantitative data was processed in Tableau, (http://www.tableau.com), and the answers to the open-ended questions were imported into NVivo software (qualitative data analysis software, http://www. qsrinternational.com/nvivo). The length of the reported stories varied remarkably from a minimum of 50 words to a maximum of 570, with an average of 246 , median of 191 , and standard deviation of 148 . The coding process consisted of several cycles (Figure 2) including structural, axial, and focused methods [52]. In the first cycle, we applied structural coding that allowed grouping the raw data into top-level categories from the survey questionnaire and resulted in two coding sets. The first set consisted of answers from Q4 and Q14-17 (Table 2) describing the most memorable stories and valuable outcomes recognized by the respondents. The second set comprised a general overview of serendipitous experiences (Q3), feelings and impressions (Q7), common interests (Q12), and ideas about ICT-enhanced serendipity (Q18-19). Next, for the first set, we conducted another round of structural coding based on the serendipitous experience process in McCay-Peet and Toms's [23] model (trigger, connection, follow-up, and valuable outcome). Then, we utilized axial coding, which included line-by-line analysis and deconstruction of the data into emerging categories for each phase of the process. Finally, focused coding was applied to identify the most frequent categories. The coding cycles were iterative and involved the three authors, who conducted the coding separately and cross-checked each other's categorizations to validate the quality of the coding structures. 


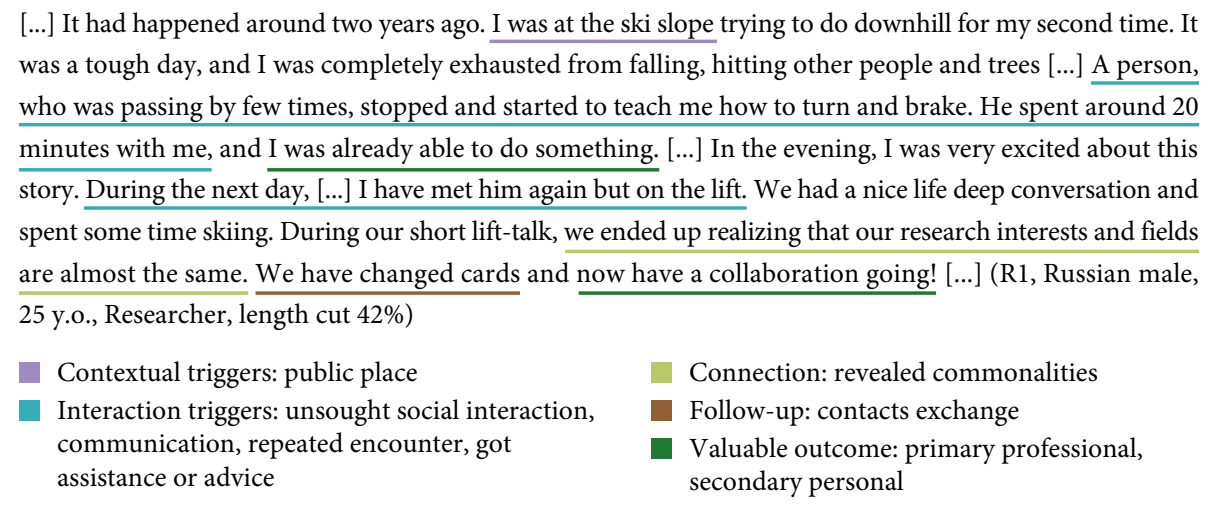

FIgURE 4: An excerpt from a respondent's story of a chance encounter during leisure activities that led to professional collaboration.

\begin{tabular}{|c|c|}
\hline IIt IOI Every & s pretty open and people are ta \\
\hline friendly. I kept bumping into a person, an & e were just having short chats and talks. So, or \\
\hline as I was waiting for my tea, I bumped int & lleague, and he started to tell me in detail what \\
\hline his startup about. One thing led to anot & cided to set a proper meeting where we $\mathrm{v}$ \\
\hline down and discuss if I could actually help & urned out that he needed someone who coul \\
\hline$\overline{\text { him with design in his current project and }}$ & that. Since then, we're still working together on \\
\hline project, and so far we're having good resu & e together. [...] (R4, Greek female, 41 y.o., Gr \\
\hline UI Designer, length cut 52\%) & \\
\hline Contextual triggers: work premises & Connection: revealed complementarity \\
\hline $\begin{array}{l}\text { Interaction triggers: communication, } \\
\text { repeated encounter }\end{array}$ & $\begin{array}{l}\text { Follow-up: repeated social interaction } \\
\text { Valuable outcome: primary professional }\end{array}$ \\
\hline
\end{tabular}

Figure 5: An excerpt from a respondent's story about how the work environment facilitated a serendipitous social encounter.

\section{Findings}

In this section, we provide an overview of the serendipitous social encounters, including quantitative and qualitative observations and examples in excerpts from the respondents' narrations. We next describe each phase of the serendipitous experiences, following the process model by McCay-Peet and Toms [23] but contextualizing it to the social aspect of unsought encounters.

4.1. Overview of the Serendipitous Encounters. The quantitative results in Figure 3 demonstrated that the majority of respondents experienced serendipitous social encounters mostly in unfamiliar environments during both physical and social contexts. In general, they were energized and positively oriented to socialize and had free time to take advantage of opportunities. Regarding personal attraction, the respondents found these interactions with other persons to be very comfortable, and they were able to identify similarities in their personalities and interests.

From an experiential viewpoint, the encounters led to various positive feelings such as excitement, thrills, curiosity, interest, and a sense of belonging and importance. As expected, due to the nature of serendipity, the majority of the respondents explicitly mentioned that they felt lucky and could not believe in such coincidences. They also interpreted their experiences as uncontrollable and unsought. Some assumed that fate or providence had enabled these encounters, while others considered them to be the results of personal traits such as openness, willingness to communicate, and the ability to step outside their comfort zone. The following example depicts how a respondent recognized both aspects-the roles of luck and individual personality traits:

"The fact that we were both talkative and we found each other quite interesting people made this possible. Besides a little bit of luck, because he was looking for someone with my set of skills. At that time, I was also very active, and it came quite naturally to me to grasp this opportunity and work with something that I found both challenging and interesting." (R4, Greek female, 41 y.o., Graphic/UI Designer)

The reported stories represented a high diversity of contextual characteristics and illustrated the entire social serendipity process, from the moment of a chance to recognize and establish value in one's professional life. The analysis of the qualitative data showed that the temporal distance between the first encounter and the positive outcomes varied from days to decades. The majority of the stories were very detailed, often with descriptions of preconditions such as personal feelings and chains of actions that led to the encounters and obtaining valuable outcomes. 


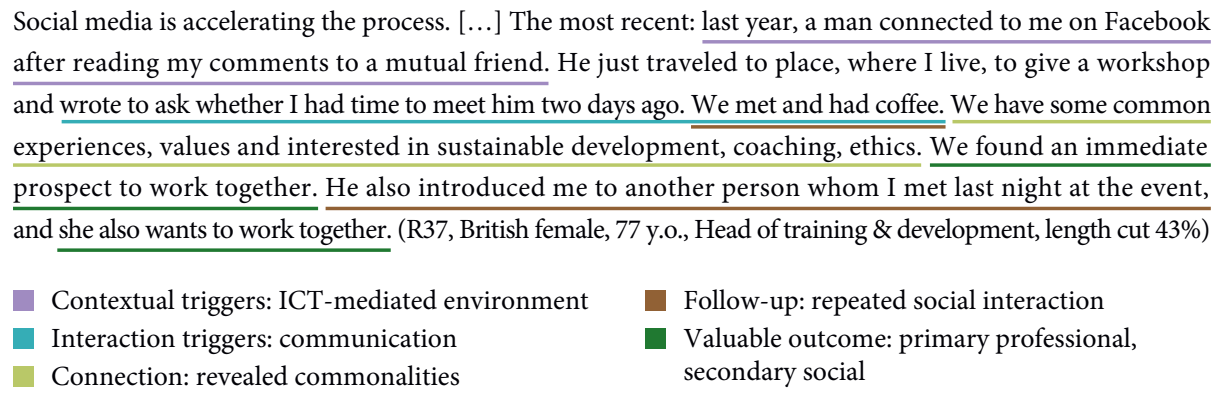

Figure 6: An excerpt from a respondent's example of an ICT-mediated environment that increased the probability of social serendipity.

TABLE 3: Categories of contextual and interaction triggers identified in the respondents' stories.

\begin{tabular}{|c|c|c|}
\hline Trigger type & Category & Examples from the stories \\
\hline \multirow{6}{*}{ Contextual } & Public place (10 stories) & $\begin{array}{l}\text { Streets, airports, clinics, train stations, hostels, bus } \\
\text { stops, saunas, cafés, and ski slopes }\end{array}$ \\
\hline & Professional event (7 stories) & Conferences, exhibitions, and seminars \\
\hline & ICT-mediated environment ( 7 stories) & $\begin{array}{c}\text { Phone and video calls, emails, and social network } \\
\text { services (e.g., Facebook) }\end{array}$ \\
\hline & Work premises (6 stories) & Kitchens, meeting rooms, offices, and halls \\
\hline & Education premises ( 5 stories) & Campus areas and group classes \\
\hline & Social event ( 2 stories $)$ & Volunteering events and fairs \\
\hline \multirow{5}{*}{ Interaction } & Direct communication (29 stories) & $\begin{array}{l}\text { Introducing each other, small talk, useful information } \\
\text { exchange, official meetings, and discussions of fields } \\
\text { of interest, problems, and opportunities }\end{array}$ \\
\hline & Repeated encounters (9 stories) & $\begin{array}{l}\text { Bumping into the same person several times, } \\
\text { attracting attention and motivating follow-up }\end{array}$ \\
\hline & & Introduction of two actors by a familiar person (e.g., a \\
\hline & Unsought interactions (9 stories) & $\begin{array}{l}\text { friend or supervisor) when they least expect it, } \\
\text { initiation of interactions by stranger }\end{array}$ \\
\hline & Receiving assistance or advice ( 8 stories) & $\begin{array}{l}\text { Assumption of the role of mentor by the recently } \\
\text { encountered person, leading to professional follow- } \\
\text { up or valuable outcomes }\end{array}$ \\
\hline
\end{tabular}

To provide a detailed picture of the collected experiences and to illustrate the coding process of the qualitative data, we selected three stories that well represented the diversity of the gathered data. The first case (Figure 4) referred to a chance encounter that was initiated during leisure activities and evolved into a serendipitous experience with professional collaboration as its valuable outcome. The informal contextual setting, combined with the respondent's problem, triggered interactions with a stranger, who not only helped in the current situation but also became a collaborator after later social interactions.

Another story demonstrated how a creative working environment could serve as a networking space and increase the probability of serendipity (Figure 5). Here, repeated encounters provided the element of surprise that motivated the actors to interact and revealed previously hidden opportunities for cooperation. The final example (Figure 6) illustrated how technology-mediated interactions in social networking services could lead to face-to-face meetings and result in the planning of professional partnership. In this context, the respondent's follow-up of the opportunity and willingness to interact played significant roles in turning chance into serendipity.
4.2. Analysis of the Social Serendipity Process. McCay-Peet and Toms's [23] model was used as a framework to identify different phases in the narratives (trigger, connection, follow-up, and valuable outcome), which determined the structure of this subsection. We created a bottom-up categorization of the different instances of each phase in the stories, supported by the examples from reported stories.

4.2.1. Triggers. In the serendipity process, a trigger constitutes a moment when a chance encounter happens. In other words, it refers to the general context, social situation, or setting that affects an encounter. Earlier research classified triggers based on sensory qualities [23] or types of objects and environments [14] due to the primary focus on unexpected encounters with information. We investigated serendipitous encounters from the perspective of making new valuable connections, so we distinguished between two types of triggers: contextual and interaction triggers. Contextual triggers refer to environmental settings that spark perceptions of serendipitous experiences, while interaction triggers cause unsought interactions with the person encountered. 
TABLE 4: Categories of the connection phase identified in the respondents' stories.

\begin{tabular}{lc}
\hline Category & Examples from the stories \\
\hline $\begin{array}{l}\text { Revealed commonalities (33 stories) } \\
\text { Revealed complementarities (17 stories) }\end{array}$ & Job fields, professional and personal interests, hobbies, life goals, work styles, shared social \\
ties, education fields, and life experiences
\end{tabular}

In this study, the most common type of contextual triggers was related to public places (Table 3 ). In addition to the example in Figure 4, the respondents reported meeting interesting others on public transportation and in train stations, restaurants, hotels, and even the streets. Other common contexts included professional events such as conferences, seminars, and professional exhibitions.

Some of the stories featured ICT-mediated environments (Figure 6) such as video conferences and Internet sites (discussion forums and websites), and the use of social media services could indeed increase the probability of unsought encounters. Many mentioned that they believed that ICT could simplify the process of finding relevant others and increase awareness of potential collaborators:

"ICT can help connecting professionals online based on, e.g., interests, professional targets, or ambitions and offer "blind date" type of connection possibilities, a little bit like "people you may know" on LinkedIn, but "people you have common interests in." I cannot really visualize the technical features other than by saying that some algorithm which can provide such "blind dates," and then based on the users' feedback learns to understand better what kind of people would more likely be useful, new encounters." (R21, Finnish male, 48 y.o., Sales Director)

One respondent went so as far as to envision computational platforms that could enable the advanced formation of genuinely global virtual collaboration communities across any demographic boundaries:

"ICT solutions might collect data about my and others' daily digital exhaust, and algorithmically finding new potential connections for me to explore. I envision, informal spaces for team-based work. I'm not talking about coworkings or lofts, but about a platform (social or virtual) where a person leading some project will be able to find and recruit, in a way, required specialists and communicate with them (no matter what language they speak or where they live)." (R29, Finnish male, 39 y.o., Researcher)

Despite the generally positive attitudes toward technology-mediated serendipity, some respondents seemed to regard existing solutions as having limited ability to facilitate follow-up activities and value creation among people:

"ICT can increase so-called coincidensity-the increase of chance encounters between a diversity of people-but in many cases, it does not support the value creation, which is the critical element in serendipity." (R32, Finnish male, 62 y.o., Founder and partner)
Additionally, the respondents were concerned about the trustworthiness of computer-mediated communication and the reliability of digital persona. Such attitude could be explained by the gap between trust in online and offline (face-to-face) interactions and the variance in this respect in different digital communication media (e.g., chats vs. video calls), as implied in the following example:

"I believe there should be a way of having social media profiles validated as accurate and trustworthy. I do trust people, but I would feel better when accepting connection requests from strangers if there was a way of checking their profile is true, similar to the blue tick that celebrities have on Twitter. [...]" (R35, British male, 48 y.o., Data architect)

In addition to contextual factors, social serendipity experiences could be initiated through unsought interactions with the encountered person, in words, through interaction triggers (Table 3). For instance, repeated encounters with the same person could easily catch one's attention (i.e., the familiar stranger) and motivate initiating interactions, possibly leading to potentially valuable outcomes. In other cases, unsought social interactions occurred when an individual was least expecting to socialize with others, increasing the perception of serendipity. The majority of the stories reported that small chats and informal discussions triggered serendipitous experience: ongoing conversations gradually led to identifying mutual interests and synergies.

Another type of interaction trigger was unsought advice or assistance. In addition to the stories represented in Figures 4-6, a representative example of interaction triggers came from the following story:

"[...] My department was taking up an international project with a foreign university. Professor asked me if I could [...] welcome the guests [...] and look after their comfort and other arrangements. Since I held him in high regard, I could not refuse. [...] When I first met them, I was hesitant, but they were very friendly. [...] We discussed our research areas and interests, and those matched well. By the time we reached the Guest House, they had developed a liking for me! Later that year, I came to know of a Ph.D. award and was encouraged by my supervisor to apply for it. [...] The first and most crucial step was to identify and approach a prospective supervisor from another country. [...] I had forgotten all about the two visitors that I assisted, but my supervisor happened to recall my pleasant meeting with them and suggested to contact them. [...] I applied for the award, got selected, and now [...] working with these two lovely and intelligent professors on my Ph.D. topic." (R6, Indian female, 26 y.o., Doctoral student, story length cut $42 \%)$ 
TABLE 5: Categories of the follow-up phase identified in the respondents' stories.

\begin{tabular}{lc}
\hline Category & Examples from the stories \\
\hline $\begin{array}{l}\text { Repeated interactions (30 stories) } \\
\text { Contact information exchanges (6 stories) }\end{array}$ & $\begin{array}{c}\text { Multiple meetings or chats that gradually lead to identification of potentially } \\
\text { valuable outcomes } \\
\text { Capturing opportunities for later, for instance, by exchanging business cards or } \\
\text { contact details }\end{array}$ \\
\hline
\end{tabular}

In other words, the respondent was compelled to interact with foreign visitors and did not expect that these connections would be useful one day. In addition, the supervisor's advice triggered the connection phase of the serendipitous experience, leading to follow-up with foreign professors and achievement of a valuable outcome.

Overall, the data revealed that chances for serendipitous social encounters could appear not only in unknown environments but also in familiar places. Although it was hardly surprising that knowledge workers met at events, it was interesting to note that the respondents also reported unsought and unexpected experiences in contexts where people were generally in socially open moods and mentally prepared for new opportunities. In addition to contextual factors, the experience of social serendipity could be initiated through interactions with other individuals and surroundings. The stories usually included multiple triggers; for example, both contextual and interaction triggers led to the next phases of the experience: connection and follow-up.

4.2.2. Connection and Follow-up. In the traditional notion of serendipity, connection refers to the phase when a person reflects on the trigger based on their background and knowledge, leading to identification of possibly valuable outcomes. In this study, connection refers to proactive, reciprocal reflection on triggers and the interactive process of obtaining an understanding of how to benefit from serendipitous social encounters. Such sense-making of the encounter is built on recognizing common ground as people get to know each other and exchange information, often during their first meeting (Table 4).

The respondents described various commonalities between themselves and their recently met persons. While the majority of the respondents referred to having similar jobs and interests in general, some specifically mentioned shared research interests. There were also some examples of identification of similar personality traits, hobbies, and even life experiences. One story brought up the similarities and differences in of a good match in which the heterogeneity of the background and viewpoints and the similarity of goals and interests had benefits for both professional and personal contexts:

"I took part in a video lecture, sitting behind a Tv-screen in a meeting room. [...] The discussions were difficult due to a bad connection, but I remember how excited I was when someone started to comment about a book related to the lecture. I had just finished it, and it had also been important for my thinking. [...] We later met face-to-face with that person, and since that day [...], we have been helping each other's growth both in personal as well as in professional life. [...] We both work on dissertations, and although they sound to be of subjects quite far from each other, we are interested in the same phenomenon, but from a different point-of-view. We also share ideological goals and interests in personal lives. [...] With quite a different background and a different logic/mindset, we have grown to the benefit of our differences and to learn from each other instead of "only" sharing similar experiences and thoughts." (R34, Finnish female, 42 y.o., Researcher, story length cut 52\%)

The connection phase was crucial to obtaining an understanding of how to benefit from a serendipitous social encounter, whether to solve urgent problems or access new opportunities or directions. However, to achieve the optimal benefit and turn pure chance into serendipity, one had to invest in the follow-up phase. In social serendipity, followup refers to the deliberate social interactions with the encountered person needed to obtain a valuable outcome. These interactions can include follow-up messaging, meetings, and more active collaboration. Thus, the connection, together with the follow-up phase, can be said to distinguish serendipity from pure luck or chance. One respondent deeply contemplated this fact:

"In all my serendipitous encounters, there are two common aspects - I have always been expecting nothing (no followup) after the first contact and so was surprised that actually, this particular case developed somehow. As a second, I always had to invest some professional and personal efforts to explore the relation and get some long-term results. [...]" (R16, Czech male, 33 y.o., Researcher, story length cut 78\%)

Our analysis identified two main categories of follow-up actions and interactions (Table 5). The first one referred to later capturing opportunities when an individual realized the possible value in the initial encounter but could not yet identify how or where to apply this potential. In our data, such actions included, for instance, the exchange of contact information. The majority of the respondents, however, focused their narrations on the process of identifying mutual benefits during repeated social interactions such as meetings and phone calls. It is worth noting that many stories had a chain of follow-up actions, possibly including a delay between the connection and follow-up actions. Often, much information needed to be exchanged before a mutually beneficial topic of collaboration was discovered.

While expecting technology to be a powerful tool for connection and follow-up interactions with recently established ties, some respondents noted that the ways in which social media platforms were designed might limit their use in the process of strengthening relationships: 
TABLE 6: Categories of valuable outcomes identified in respondents' stories.

\begin{tabular}{lc}
\hline Category & Examples from the stories \\
\hline $\begin{array}{l}\text { Primary-professional (37 stories) } \\
\text { Secondary-social and personal (16 stories) }\end{array}$ & $\begin{array}{c}\text { Professional collaboration, vocational growth, business partnership, and career } \\
\text { planning }\end{array}$ \\
& $\begin{array}{c}\text { Friendship, extended social networks, mentoring, useful information retrieval, self- } \\
\text { improvement, graduation, and educational awards }\end{array}$ \\
\hline
\end{tabular}

\begin{abstract}
"I would like to know more about my network, but at the moment it is very superficial, I see only a page with a few works and a list of their education and experience. It tells me little about their personality, their hopes and expectations, their goals and aspirations. As a consequence, I have many contacts but not so many friends or people I know personally. I think faster networks and virtual reality meetings will help to create lasting impressions and build stronger relationships. I regret that I can only text message to my LinkedIn contacts when a short virtual face-to-face meeting would be much nicer and more humane." (R35, British male, 48 y.o., Data architect)
\end{abstract}

4.2.3. Valuable Outcomes. Valuable outcomes refer to the positive outcomes of serendipitous social encounters. All the analyzed stories resulted in professionally valuable outcomes, and some were also followed by additional personal and social benefits (Table 6). The valuable professional outcomes included examples of collaboration and partnering, gaining employed, changing jobs, and deciding on career directions. In fact, in some cases, an encountered person became not only a work partner but also a good friend in personal life. Some respondents explained that the encounters helped them build and extend their social networks, while others cited personal achievements as benefits. For instance, when assisted with useful information, one might gain support to finalize one's education or obtain educational rewards. Finally, the respondents also mentioned self-improvement, referring to learning new perspectives, getting additional training, solving personal problems, improving professional skills, and changing one's worldview and behavior for better. We consider this spectrum of beneficial outcomes to consolidate the idea of serendipity as a fruitful experience to universally seek in professional life.

The respondents mentioned that not only chance or luck led to beneficial outcomes. Other relevant aspects of serendipity included, for instance, openness to new opportunities, curiosity, personal experiences, and professional skills, which allowed taking advantage of serendipitous encounters: "Many chance encounters do not lead onto anything sig-
nificant beyond a pleasant encounter, professionally or
personally, but occasionally a relationship can lead to a
meaningful and important event or significant change. [...]
For instance, when a chance encounter in a corridor in a
building led me to become involved in a predictive analytics
project for a business partner. Such events do not happen
often, but they happen with sufficient regularity that I am
minded to network with people and be open to new possibilities [...]" (R35, British male, 48 y.o., Data architect, story length cut $61 \%)$

Individual qualities were essential to realize the opportunity for a fortunate encounter and benefit from serendipity. For example, openness was needed to have the appropriate mindset and experience to perceive the opportune moment. In other words, impact took place when there was a space for it in one's life.

\section{Discussion}

The results imply that knowledge workers' experiences of serendipitous social interactions manifest in various situations beyond organizational boundaries and offer a wide range of perceived benefits. The data also demonstrate the diversity of the contexts of the encounters and the triggers that affect the matching process. The subjectivity of drawing a line between serendipity and mere luck results in variance in the intensity of the experiences and effects the respondents included in their stories. With our survey design and recruitment efforts, we managed to gather relatively strong experiences of social serendipity. However, we expect that we were unable to collect other more mundane instances of these experiences. In the following, we highlight a few of our qualitative findings that we consider to best characterize the concept of social serendipity. In addition, we discuss the seemingly minor role of technology in social serendipity and outline design directions to enhance serendipitous experiences with technology. Finally, we address the methodological limitations of the study.

5.1. Key Characteristics of Social Serendipity. The first characteristic addressed is that social serendipity can be seen as an instance of aesthetic experience [53]. To be more specific, serendipity is a well-formed, complete experience that is subjectively unified, recognized, and interpreted. It has a beginning and an end and unfolds over time, producing a satisfying emotional quality - the joy of unsought fortune-that permeates the entire process. The flow of the serendipitous experience thus is characterized by the purposeful connection of all phases coupled with the subject's actions and interactions with the physical and social environments. In the following, we reflect on each phase of social serendipity identified in the stories and contrast them to earlier research on the conceptualization of serendipity.

Theorizing serendipity, researchers $[14,23]$ revealed types of triggers that make sense in the context of information retrieval in which the experienced outcome generally relates to knowledge discoveries. In contrast, social 
serendipity consists of building valuable interpersonal relationships and thus is primarily driven by interactions between people. Our findings, therefore, distinguish between contextual and interaction triggers. The stories indicate that experience is rarely sparked by only one type of a trigger but instead is more commonly caused by a complex combination of several triggers. While contextual triggers create a fruitful scene for serendipity to occur, interaction triggers play a more significant role in the experiences of serendipitous encounters because they lead to the next phases.

In a traditional notion of information serendipity, the connection phase is characterized by unconscious processing of the triggers and content, but our findings on social serendipity demonstrate the qualities of proactive and reciprocal sense-making. The connection phase in interpersonal interactions centers on two primary approaches: through direct social interactions, people either reflect on commonalities between each other (e.g., to build trust) or look for complementary characteristics (e.g., to identify reasons to collaborate). The stories present two types of follow-up actions and interactions: (i) repeated social interactions to strengthen connections and explore mutual benefits; and (ii) exchanges of contact information to capture opportunities for later use. To turn pure luck and chance into social serendipity, both actors have to invest effort and commitment during the connection and follow-up phases.

As mentioned, the outcomes in the traditional notion of serendipity generally are related to knowledge discovery. Of course, in social serendipity, knowledge discovery is also one of the benefits complementing the primary value: new beneficial relationships with other people. In fact, making meaningful connections with other people contributes to information flow and knowledge creation. All the examples from our survey aimed at collecting stories about serendipity in professional life explicitly refer to work-related benefits (e.g., finding new jobs and collaborators) as the major valuable outcomes. However, many stories indicate that professional gains are often accompanied by secondary benefits (e.g., friendship, mentoring, and self-improvement), which enable even stronger social bonding. Moreover, recognizing that one is experiencing social serendipity and the related satisfying emotional qualities can be perceived as beneficial outcomes of the experience.

\subsection{The Role of Technologyin Social Serendipity. As addressed} in Section 2, earlier HCI research demonstrated considerable interest in developing ICT to support social matching and chance encounters. Although only a few narrations highlight the role of technology in contributing to these experiences, the respondents believed that ICT can help identify opportunities for serendipitous professional collaboration and assist in matching and communication processes. While this study does not allow generalizing the prevalence of ICT in knowledge workers' experiences of social serendipity, the minor role of technology in this sample highlights the importance of reconsidering what kinds of computational approaches can more effectively foster serendipitous social encounters. We claim that the presented empirical findings on the social serendipity process can support the definition of meaningful design goals and directions for future ICT. We especially apply our thinking to social matching services [54] and people recommender systems [55] because they both represent a more proactive paradigm of technology. In addition to presenting relevant information, such technologies make complex inferences and use algorithmic logic to suggest alternatives to users and actively help their decisionmaking.

Current matching services and people recommender systems often employ algorithms based on two well-established social networking mechanisms. First, matching is primarily driven by the homophily hypothesis [56], which states humans tend to connect mostly with those similar to themselves. Second, they follow the triadic closure hypothesis, which holds that new connections are likely to form between friends-of-friends [57], that is, between actors who already have strong, trustworthy ties [58]. The human preference for like-minded others and trust in new connections introduced by familiar others are even visible across some stories collected in this study. However, these principles might be detrimental to knowledge work because they contribute to the formation of social groups that consolidate viewpoints, thus reducing the creation and distribution of new knowledge and opinions. This phenomenon is referred to as an echo chamber [59], and social media services have recently received criticism for supporting echo chambers [60].

Responding to these challenges, researchers in the domain of recommender systems have started to promote serendipity as a feature that design should support [20]. The primary objective of such serendipity-enhancing systems is to increase the quality of recommendations by diversifying content and enabling novelty and unexpectedness. Diversification of the recommended content can increase the probability of serendipity but does not always lead users to perceive it. After all, intentionally using digital artifacts to identify new potential connections inherently reduces the element of unexpectedness. de Melo [14] claimed that to provoke serendipitous experiences, systems have to implement all three qualities-new discoveries, unpredictability, and value. While the first two qualities can be achieved through approaches such as randomization [61, 62] and defamiliarization $[63,64]$, facilitating the creation of value for the user is the most challenging task.

Inspired by de Melo's notion of serendipitous systems [14], we call for digital services that can contribute to the entire processes of social serendipity. We propose a usercentric idea of ICT-enhanced social serendipity experiences with three vital process-based elements: (i) an initial phase of introducing opportunities for professional networking and interpreting their inferred relevance, (ii) encouraging direct social interactions for value creation, and (iii) maintaining social awareness of established connections through facilitated follow-up processes. In the following, we discuss these elements in relation to potential computational service qualities. We primarily focus on aspects relevant to the $\mathrm{HCI}$ community. 
5.2.1. Introducing Opportunities and Facilitating the Interpretation of Inferred Relevance. Our findings imply that experiences of social serendipity are often initiated in unsought, face-to-face chats and discussions. Optimistic expectations of how computer-mediated communication might lead to serendipity were rare among the respondents, and most thought that the first interactions should take place face-to-face to establish social bonding and trust. These findings could be explained by the fact that many of the respondents were middle-aged or older citizens possibly less trustful and open to the use of technology than millennials [65].

Indeed, in virtual environments, many issues tend to limit interactions with unfamiliar people. For instance, privacy restrictions might inhibit making new connections. The lower psychological pleasure from computer-mediated communication than face-to-face interactions might reduce motivation to chat with strangers. The lack of exploratory, open-minded social settings in virtual environments might hinder people from investing sufficient time for exploring networking opportunities and mutual interests. In the early phases of the social serendipity process, the probability of experiencing the unexpected depends on the content such as other users' profiles and their presentation in the user interface. In people recommender systems, the degree of how surprising and seemingly relevant the suggested new contacts are can affect users' acceptance and willingness to interact with them.

The current standard of introducing people to each other in social network platforms (e.g., recommendations of whom to connect to or follow) is based on a simplistic, listbased approach using profile pictures, names, and brief biographical summaries. This way of delivering recommendations can be enough for lightweight, low-risk decisions, such as whom to follow or to identify existing acquaintances on a platform. However, due to the various needs of partnering and collaboration (e.g., from seeking a mentor for personal vocational growth to building a community), finding valuable, meaningful people in knowledge work requires enhanced content and profiling and advanced visualization techniques to deliver recommendations. In this regard, the variety of data about people available in social media services could help build more comprehensive user profiles and analyze existing ties in the larger social network [66]. Social network analysis could also enable computational identification of potentially relevant new and weak ties. On a broad level, interactive, exploration-supporting visualization of several perspectives of potential collaborators in a social network graph could facilitate the experience of surprise and luck. Positioning a user in a social graph and explaining the inferred relevance with recommended people (e.g., by visualizing the similarities and differences mentioned by R34) thus could trigger serendipity and lead to the connection phase.

The connection phase is primarily a mental process of analyzing information about the new encounters and reflecting on and interpreting the potential value of prospective interactions. To support this phase in ICT-mediated environments, it is essential to create a smooth transition to social interactions, first making users familiar with each other through enhanced profiling. This calls for identifying the types of content that, first, best suit the diverse contexts of professional matching and that, second, knowledge workers consider to be sufficiently valuable to start interacting with an unfamiliar match. In this case, user profiles should present content that steers readers' attention to users' qualities that are timely and relevant to understand, thereby initiating social interactions. Self-created content could be complemented with computational analysis of personal social data and extended with insights inferred from different digital platforms and social media services. Enriching each user's image could be useful to identify unanticipated opportunities, inherent personal qualities, and contextual oddities [67], attributes that might not appear in usergenerated content.

\subsubsection{Encouragement and Persuasiveness for Value Creation} and Maintenance of Social Awareness. The findings imply that even in face-to-face interactions, encounters that result in serendipity could benefit from the tertius iungens orientation [68], or facilitators to encourage, initiate, and coordinate interactions with new people and motivators to follow up contacts. In addition to recommending seemingly relevant new connections (i.e., increasing chances), ICT could also facilitate the connection phase and aid identification of potentially beneficial outcomes. While designing for various encouraging features (i.e., persuasiveness) in ICT applications is tempting, achieving an acceptable yet useful degree of persuasion is highly challenging. Current people recommender systems in social media services can be considered to have a reasonably reliable ability to suggest a variety of opportunities, but they have no role in converting these recommendations into actual behavior.

Designing ways to motivate users to perform the necessary actions on the path to realize possible social serendipity calls for audacious design exploration. We propose that this role could be best realized through cooperative synergy between a data-driven analytics system focused on computational analysis and a user capable of making personally relevant interpretations and focusing on the qualitative aspects of social matching. Thus, ICT-enhanced social serendipity could be aimed at achieving human-in-the-loop analytics [69] and augmented intelligence [70, 71] rather than artificial intelligence, that is, supplementing human intelligence with computational capabilities through new forms of HCI. The innate differences between human decision-making and computational logic necessitate careful design of the interplay of these two types of intelligence [72]. For example, considering the well-known paradox of choice [73], instead of increasing the numbers of matching opportunities, perhaps ICT applications should reduce choice anxiety by radically limiting the options of suitable individuals or giving users efficient ways to do so reflectively and systematically.

For example, ICT could provide cues regarding its inferences of how a given social recommendation is relevant to the target user and deliver so-called tickets to talk to initiate 
discussions and maintain already established ties. Furthermore, as the findings demonstrate, valuable outcomes are generally achieved after long-term follow-up activities, sometimes over the course of several decades. To maintain interpersonal relationships and to support value creation among users, one suitable approach could be to keep users updated on their recommended contacts' recent activities and to inform users of suitable opportunities for face-to-face and virtual meetings. Supporting users in understanding the value of their new and existing connections could be achieved by utilizing advanced personalization approaches. The system could adjust the appearance of users' profiles and contents, gradually revealing more facts about them (enabling the element of surprise) and potentially encouraging direct communication and follow-up avenues. Moreover, by collecting users' feedback on new adaptive profile representations, matching algorithms could learn individuals' preferences and criteria for subjectively perceived relevance. This personalization approach could imitate the repeated encounter triggers revealed in the sample data and thus enhance people's decision-making process in the choice of better matching opportunities for value creation.

5.3. Methodological Limitations. All methodologies impose different limitations on the reliability and validity of findings. In this study, for example, an online survey might not have been considered to be ideal for qualitative research. The sampling could be challenging to control, compromising generalizability, and the truthfulness of the answers could not be verified as in face-to-face interviews. However, the choice to run an online survey with open-ended questions was considered to be the most suitable compromise between the research objectives and practicality. On the one hand, the research gap and our questions called for qualitative accounts to deeply describe and understand the subjective experiences and reported social encounters. On the other hand, the prevalence of knowledge workers' memorable serendipitous social encounters was considered to be relatively low, making recruitment for an interview-based study highly challenging on a practical level. Furthermore, as the respondents self-reported past experiences, recall bias very likely influenced the truthfulness of the reported experiences. This, however, was inevitable because serendipity, in fact, required time to progress and so could hardly be studied as it unfolded.

Despite extensive recruiting efforts, attracting respondents proved to be challenging, which could be seen to support our assumption of the rarity of such experiences. Fortunately, the analyzed responses were very detailed and represented relatively strong, vivid examples of serendipity, which allowed in-depth accounts of the experiences. We speculated that the difficulties gathering data resulted from two main factors. First, some survey visitors might not have understood the concept of serendipity or correlated it with their own experiences. The term has been relatively little used outside academia, especially compared to other related concepts. We anticipated this issue upfront, so the survey introduction also used terms like "chance" and "unexpected encounters that lead to valuable outcome." The welcome page of the survey explained what we sought in layperson's terms. Second, the individual variance in perceiving unexpected [74] might have been another factor preventing people to recognize serendipity. The concept of serendipity was related to chance and luck, so some people may have wrongly assumed that a lack of control was a fundamental element in such experiences. For instance, people with a high locus of control [75] might not have attributed such experiences to chance but, instead, considered beneficial encounters to have resulted from their own efforts and decisions. Little research has addressed cultural differences on the experience of luck and unexpectedness, so we could not assess how well this sample with a specific cultural bias represented the entire human population. Nevertheless, as this study was not aimed at producing generalizable quantitative information (e.g., the prevalence of the phenomenon), we believed that the downsides were tolerable given the seemingly rare research on experiences of social serendipity in knowledge work.

\section{Conclusions}

Serendipity has been actively theorized in the context of information retrieval, but social serendipity has not been extensively studied with empirical approaches. We conducted an international, qualitative online survey and gathered 37 responses with rich examples of serendipitous social encounters. Our analysis reveals various insights into the nature of social serendipity in the context of knowledge work. In addition to reporting a wide range of aspects and subjective experiences relevant to social serendipity, we extend the theoretical understanding of the serendipity process with aspects particularly applicable to serendipity in social contexts. The gathered insights can be employed to inform the design of more effective and appropriate ICT. While luck and unexpectedness characterize any chance encounters, social serendipity also requires active followup to identify their potentially valuable outcomes and active collaboration to realize them. Social serendipity benefits from repeated encounters, social facilitation, and identification of shared goals and reciprocal benefits. Interestingly, however, only a few of the respondents reported that ICT served in roles that somehow contributed to the emergence or support of serendipitous encounters. We, therefore, highlight the question of the meaningful roles of ICT in computationally enabled social serendipity experiences.

\section{Data Availability}

The data generated or analyzed during this study are included in this article.

\section{Conflicts of Interest}

The authors declare that they have no conflicts of interest. 


\section{Acknowledgments}

This work was funded by the Business Finland Project Big Match (3166/31/2017 and 3074/31/2017). The authors thank all members of the Big Match project and the participants of the study.

\section{References}

[1] L. A. Goodman, "Notes on the etymology of serendipity and some related philogical observations," Modern Language Notes, vol. 76, no. 5, pp. 454-457, 1961.

[2] R. K. Merton and E. Barber, The Travels and Adventures of Serendipity: A Study in Sociological Semantics and the Sociology of Science, Princeton University Press, Princeton, NJ, USA, 2006.

[3] D. Liestman, "Chance in the midst of design: approaches to library research serendipity," $R Q$, vol. 31, no. 4, pp. 524-532, 1992.

[4] A. Ferguson, "The lost land of serendip," Forbes, vol. 164, no. 8, pp. 193-194, 1999.

[5] T. D. Anderson, "Beyond eureka moments: supporting the invisible work of creativity and innovation," Information Research: An International Electronic Journal, vol. 16, no. 1, pp. 1-24, 2011.

[6] S. Johnson, Where Good Ideas Come from: The Seven Patterns of Innovation, Penguin, London, UK, 2011.

[7] N. K. Agarwal, "Towards a definition of serendipity in information behaviour," Information Research: An International Electronic Journal, vol. 20, no. 3, pp. 1-16, 2015.

[8] D. Bawden, "Encountering on the road to serendip? Browsing in new information environments," in Innovations in Information Retrieval: Perspectives for Theory and Practice, pp. 122, Facet Publishing, London, UK, 2011.

[9] I. Buchem, "Serendipitous learning: recognizing and fostering the potential of microblogging," Form@ re-Open Journal per la formazione in Rete, vol. 11, no. 74, pp. 7-16, 2011.

[10] J. E. Nutefall and P. M. Ryder, "The serendipitous research process," The Journal of Academic Librarianship, vol. 36, no. 3, pp. 228-234, 2010.

[11] S. E. Alcock, "The stratigraphy of serendipity," in Serendipity: Fortune and the Prepared Mind, M. de Rond and I. Morley, Eds., pp. 11-26, Cambridge University Press, Cambridge, UK, 2010.

[12] J. E. H. Bright, R. G. L. Pryor, and L. Harpham, "The role of chance events in career decision making," Journal of Vocational Behavior, vol. 66, no. 3, pp. 561-576, 2005.

[13] V. L. Rubin, J. Burkell, and A. Quan-Haase, "Facets of serendipity in everyday chance encounters: a grounded theory approach to blog analysis," Information Research, vol. 16, no. 3, p. 27, 2011.

[14] R. M. C. de Melo, On serendipity in the digital medium: towards a framework for valuable unpredictability in interaction design, Ph.D. thesis, Faculdade de Belas Artes, Universidade do Porto, Porto, Portugal, 2018.

[15] S. Kiesler and J. N. Cummings, "What do we know about proximity and distance in work groups?" in Distributed Work, pp. 57-80, MIT Press, Cambridge, MA, USA, 2002.

[16] D. Vyas, A. Dix, and G. C. van der Veer, "Reflections and encounters: exploring awareness in an academic environment," Computer Supported Cooperative Work (CSCW), vol. 24, no. 4, pp. 277-317, 2015.

[17] P. Jeffrey and A. McGrath, "Sharing serendipity in the workplace," in Proceedings of the Third International
Conference on Collaborative Virtual Environments, pp. 173179, ACM, San Francisco, USA, September 2000.

[18] I. Leo, M. De Gemmis, P. Lops, G. Semeraro, M. Filannino, and P. Molino, "Introducing serendipity in a content-based recommender system," in Proceedings of the Eighth International Conference on Hybrid Intelligent Systems (HIS'08), pp. 168-173, IEEE, Barcelona, Spain, September 2008.

[19] I. Leo, M. de Gemmis, P. Lops, G. Semeraro, and P. Molino, "Can a recommender system induce serendipitous encounters?" in E-commerce, pp. 239-245, InTech, London, UK, 2010.

[20] P. Adamopoulos and T. Alexander, "On unexpectedness in recommender systems: or how to better expect the unexpected," ACM Transactions on Intelligent Systems and Technology (TIST), vol. 5, no. 4, pp. 1-32, 2014.

[21] S. Makri and A. Blandford, "What is serendipity? A workshop report," Information Research, vol. 16, no. 3, p. 491, 2011.

[22] A. Pease, S. Colton, R. Ramezani, J. W. Charnley, and K. Reed, "A discussion on serendipity in creative systems," in Proceedings of the Fourth International Conference on Computational Creativity, pp. 64-71, The University of Sydney, Sydney, Australia, June 2013.

[23] L. McCay-Peet and E. G. Toms, "Investigating serendipity: how it unfolds and what may influence it," Journal of the Association for Information Science and Technology, vol. 66, no. 7, pp. 1463-1476, 2015.

[24] S. Frenkel, M. Korczynski, L. Donoghue, and K. Shire, "Reconstituting work: trends towards knowledge work and infonormative control," Work, Employment \& Society, vol. 9, no. 4, pp. 773-796, 1995.

[25] T. H. Davenport, Thinking for a Living: How to Get Better Performances and Results from Knowledge Workers, Harvard Business Press, Boston, MA, US, 2005.

[26] D. Skyrme, Knowledge Networking: Creating the Collaborative Enterprise, Routledge, London, UK, 2007.

[27] K. Valkokari, "Business, innovation, and knowledge ecosystems: how they differ and how to survive and thrive within them," Technology Innovation Management Review, vol. 5, no. 8, pp. 17-24, 2015.

[28] M. G. Russell, J. Huhtamäki, K. Still, N. Rubens, and R. C. Basole, "Relational capital for shared vision in innovation ecosystems," Triple Helix: A Journal of University-Industry-Government Innovation and Entrepreneurship, vol. 2, no. 1, p. 36, 2015.

[29] G. Schreyögg and J. Sydow, "Crossroads-organizing for fluidity? Dilemmas of new organizational forms," Organization Science, vol. 21, no. 6, pp. 1251-1262, 2010.

[30] M. Arena, R. Cross, J. Sims, and M. Uhl-Bien, "How to catalyze innovation in your organization," MIT Sloan Management Review, vol. 58, no. 4, pp. 38-48, 2017.

[31] M. F. Bosenman, "Serendipity and scientific discovery," The Journal of Creative Behavior, vol. 22, no. 2, pp. 132-138, 1988.

[32] P. V. Andel, "Anatomy of the unsought finding: serendipity: orgin, history, domains, traditions, appearances, patterns and programmability," The British Journal for the Philosophy of Science, vol. 45, no. 2, pp. 631-648, 1994.

[33] R.-H. Liang, "Designing for unexpected encounters with digital products: case studies of serendipity as felt experience," International Journal of Design, vol. 6, no. 1, pp. 41-58, 2012.

[34] X. Sun, S. Sharples, and S. Makri, "A user-centred mobile diary study approach to understanding serendipity in information research," Information Research, vol. 16, no. 3, p. 492, 2011.

[35] X. Zhou, X. Sun, Q. Wang, and S. Sharples, “A context-based study of serendipity in information research among Chinese 
scholars," Journal of Documentation, vol. 74, no. 3, pp. 526555, 2018.

[36] J. Dewey, Experience and Nature, Literary Licensing, Whitefish, MO, USA, 2013.

[37] K. Martin and A. Quan-Haase, “"A process of controlled serendipity": an exploratory study of historians' and digital historians' experiences of serendipity in digital environments," Proceedings of the Association for Information Science and Technology, vol. 54, no. 1, pp. 289-297, 2017.

[38] R. M. C. de Melo, Call to Adventure: Designing for Online Serendipity, Master's thesis, Faculdade de Belas Artes, Universidade do Porto, Porto, Portugal, 2012.

[39] C. Lutz, C. Pieter Hoffmann, and M. Meckel, "Online serendipity: a contextual differentiation of antecedents and outcomes," Journal of the Association for Information Science and Technology, vol. 68, no. 7, pp. 1698-1710, 2017.

[40] L. Björneborn, "Three key affordances for serendipity: toward a framework connecting environmental and personal factors in serendipitous encounters," Journal of Documentation, vol. 73, no. 5, pp. 1053-1081, 2017.

[41] L. McCay-Peet and A. Quan-Haase, "The influence of features and demographics on the perception of twitter as a serendipitous environment," in Proceedings of the 27th ACM Conference on Hypertext and Social Media, pp. 333-335, ACM, Nova Scotia, Canada, July 2016.

[42] C. Lutz, M. Meckel, and G. Ranzini, "Trusted surprises?: antecedents of serendipitous encounters online," in Proceedings of the 63rd Annual Conference of the ICA International Communication Association, p. 32, ICA International Communication Association, London, UK, March 2013.

[43] C. Brown, C. Efstratiou, I. Leontiadis, D. Quercia, and C. Mascolo, "Tracking serendipitous interactions: how individual cultures shape the office," in Proceedings of the 17th ACM conference on Computer Supported Cooperative Work \& Social Computing, pp. 1072-1081, ACM, Baltimore, MD, USA, February 2014.

[44] T. Erickson and W. A. Kellogg, "Social translucence: an approach to designing systems that support social processes," ACM Transactions on Computer-Human Interaction, vol. 7 , no. 1, pp. 59-83, 2000.

[45] J. M. Mayer, "Is there a place for serendipitous introductions?" in Proceedings of the Companion Publication of the 17th ACM Conference on Computer Supported Cooperative Work \& Social Computing, pp. 73-76, ACM, Baltimore, MD, USA, February 2014.

[46] J. M. Mayer, Q. Jones, and S. R. Hiltz, "Identifying opportunities for valuable encounters: toward context-aware social matching systems," ACM Transactions on Information Systems, vol. 34, no. 1, pp. 1-32, 2015.

[47] N. Eagle and A. Pentland, "Social serendipity: mobilizing social software," IEEE Pervasive Computing, vol. 4, no. 2, pp. 28-34, 2005.

[48] J. C. Losada, W. Creixell, T. Arredondo, P. Olivares, and R. María Benito, "Serendipity in social networks," Networks and Heterogeneous Media, vol. 7, no. 3, pp. 363-371, 2012.

[49] Xi Niu and F. Abbas, "A framework for computational serendipity," in Proceedings of the Adjunct Publication of the 25th Conference on User Modeling, Adaptation and Personalization, pp. 360-363, ACM, Bratislava, Slovakia, July 2017.

[50] R. V. D. Hoff, Mastering the Global Transition on Our Way to Society 3.0, Lindonk \& de Bres, Amsterdam, Netherlands, 2014.

[51] T. Olsson, J. Huhtamäki, and H. Kärkkäinen, "Directions for professional social matching systems," Communications of the ACM, vol. 63, no. 2, pp. 60-69, 2020.
[52] J. Saldaña, The Coding Manual for Qualitative Researchers, SAGE, Newcastle upon Tyne, UK, 2015.

[53] J. Bardzell and S. Bardzell, "Humanistic HCI," Synthesis Lectures on Human-Centered Informatics, vol. 8, no. 4, pp. 1-185, 2015.

[54] L. Terveen and D. W. McDonald, "Social matching: a framework and research agenda," ACM Transactions on Computer-Human Interaction (TOCHI), vol. 12, no. 3, pp. 401-434, 2005.

[55] C.-H. Tsai and B. Peter, "Beyond the ranked list: user-driven exploration and diversification of social recommendation," in Proceedings of the 23rd International Conference on Intelligent User Interfaces, pp. 239-250, ACM, Tokyo, Japan, March 2018.

[56] M. McPherson, L. Smith-Lovin, and J. M. Cook, "Birds of a feather: homophily in social networks," Annual Review of Sociology, vol. 27, no. 1, pp. 415-444, 2001.

[57] D. Easley and J. Kleinberg, "Networks, crowds, and markets: reasoning about a highly connected world," Significance, vol. 9, pp. 43-44, 2012.

[58] M. S. Granovetter, "The strength of weak ties," American Journal of Sociology, vol. 6, no. 78, pp. 1360-1380, 1973.

[59] A. Pentland, "Beyond the echo chamber," Harvard Business Review, vol. 11, no. 91, p. 80, 2013.

[60] M. Del Vicario, G. Vivaldo, A. Bessi et al., "Echo chambers: emotional contagion and group polarization on facebook," Scientific Reports, vol. 6, no. 1, pp. 1-12, 2016.

[61] T. Leong, S. Howard, and F. Vetere, "Feature take a chance on me: using randomness for the design of digital devices," Interactions, vol. 15, no. 3, pp. 16-19, 2008.

[62] L. Tuck, Understanding Serendipitous Experiences When Interacting with Personal Digital Content, University of Melbourne, Department of Information Systems, Melbourne, Australia, 2009.

[63] L. Tuck, R. Harper, and T. Regan, "Nudging towards serendipity: a case with personal digital photos," in Proceedings of the 25th BCS Conference on Human-Computer Interaction, pp. 385-394, British Computer Society, Newcastle, UK, July 2011.

[64] J. Bardzell, "Critical and cultural approaches to HCI," in The SAGE Handbook of Digital Technology Research, pp. 130-143, SAGE, Newcastle upon Tyne, UK, 2013.

[65] K. K. Myers and K. Sadaghiani, "Millennials in the workplace: a communication perspective on millennials' organizational relationships and performance," Journal of Business and Psychology, vol. 25, no. 2, pp. 225-238, 2010.

[66] E. Olshannikova, T. Olsson, J. Huhtamäki, and H. Kärkkäinen, "Conceptualizing big social data," Journal of Big Data, vol. 4, no. 1, p. 3, 2017.

[67] J. M. Mayer, S. R. Hiltz, L. Barkhuus, K. Väänänen, and Q. Jones, "Supporting opportunities for context-aware social matching: an experience sampling study," in Proceedings of the 2016 CHI Conference on Human Factors in Computing Systems, pp. 2430-2441, ACM, San Jose, CA, USA, May 2016.

[68] D. Obstfeld, "Social networks, the tertius iungens orientation, and involvement in innovation," Administrative Science Quarterly, vol. 50, no. 1, pp. 100-130, 2005.

[69] A. Endert, M. S. Hossain, N. Ramakrishnan, C. North, P. Fiaux, and C. Andrews, "The human is the loop: new directions for visual analytics," Journal of Intelligent Information Systems, vol. 43, no. 3, pp. 411-435, 2014.

[70] N.-N. Zheng, Z.-Y. Liu, P.-J. Ren et al., "Hybrid-augmented intelligence: collaboration and cognition," Frontiers of 
Information Technology \& Electronic Engineering, vol. 18, no. 2, pp. 153-179, 2017.

[71] J. M. Corrigan, "Augmented intelligence-the new AI-unleashing human capabilities in knowledge work," in Proceedings of the 34th International Conference on Software Engineering, pp. 1285-1288, IEEE Press, Zurich, Switzerland, June 2012.

[72] B. Scassellati and K. M. Tsui, "Co-robots: humans and robots operating as partners: the confluence of engineering-based robotics and human-centered application domains," Handbook of Science and Technology Convergence, Springer, Cham, Switzerland, pp. 1-10, 2014.

[73] B. Schwartz, The Paradox of Choice: Why More Is Less, HarperCollins, New York, USA, Revised edition, 2009.

[74] L. McCay-Peet, E. G. Toms, and E. K. Kelloway, "Examination of relationships among serendipity, the environment, and individual differences," Information Processing \& Management, vol. 51, no. 4, pp. 391-412, 2015.

[75] H. M. Lefcourt, Locus of Control: Current Trends in Theory \& Research, Psychology Press, Hove, UK, 2014. 